\title{
Reflecting on Power Relationships in the 'Doing' of Rural Cultural Research
}

\author{
RAE DUFTY
}

-INTRODUCTION

It is late February 2005 and I am sitting in Jenny's lounge room. ${ }^{1}$ Jenny is one of the female public housing tenants I am interviewing as part of my doctoral research on (as it then was) the gendered experiences of rural public housing communities. Jenny has lived in her home for eighteen years. Outside it is a forty-plus degree Celsius day; however, when I arrived an hour earlier I discovered that Jenny had decided that we should have lunch before the interview takes place. After lunch, as we sit in the lounge room, I ask Jenny whether she received a copy of the interview questions I had sent the week previously. She confirms she had but tells me she has mislaid it, so I provide her with a spare copy. Jenny, reading the interview questions aloud, goes straight into answering these questions. Used to being the 'questioner', the one controlling the interview, I am caught out and hurry to set up the digital recorder and start jotting down notes. When I can, I try to interrupt, to clarify something Jenny has said as she ploughs through the questions. Jenny treats the interview with a businesslike familiarity, and has definite ideas of what are good questions ('why are you asking this?') and what the final research project should be advocating ('well this is what I think the Government/Department should do ...'). After the interview I am struck by how little control over that particular research 
encounter I had. As I mull over this situation I realise that all the interview interactions in this research have been subtly infused with my fear of the interview falling flat and a desire to 'please' the participant(s). While not disregarding differences, material and otherwise, the exhortations that I have encountered in various critical academic literature to be 'reflexive' and to seek to 'empower' the research participant seem strangely out of place in this situation and I wondered why that is the case.

Reflecting on my own experiences of 'doing' rural cultural research, this article returns to the issue of 'power' and how it is approached in poststructuralist and feminist methodological literatures in cultural geography and rural cultural studies. $^{2}$ Specifically using a Foucaultian understanding of power, the article interrogates the theoretically inconsistent ways this understanding of power has been applied to the 'doing' of research. I then go on to investigate the implications of this regarding how we understand, reflect on and represent research relationships.

—MOVING BEYOND THE DICHOTOMY OF THE 'POWERFUL EXPERT' AND THE 'POWERLESS SUBJECT'

In cultural geography and rural cultural studies, the 'doing' of research has been transformed by poststructuralist and feminist critiques of how we produce and understand knowledge. ${ }^{3}$ This has specifically involved rejection of the positivist understanding of knowledges as produced by objective researchers, whose analyses of the data collected were considered to be impartial and 'true' representations of 'reality'. Also of concern was that positivist approaches sought to erase the research relationship, constructing the necessary interactions between the researcher and the researched as an irrelevant aspect of the data produced from such engagements. Last, positivist rationalisations of the research relationship often resulted in the valuable and important role participants had in the research process going unacknowledged or being disregarded. These attitudes meant that the researcher and research process were more likely to exploit participants and/or be insensitive to the negative impact of research that could plague participants long after the researcher had left the field.

Poststructuralist and feminist research sought to undermine this understanding of knowledge production by constructing knowledge as situated and partial. Poststructuralist rethinking of power, in particular Michel Foucault's 
contributions to these developments, has been influential in informing this methodological shift. ${ }^{4}$ A central premise of this retheorisation of power was the recognition that power and knowledge were inextricably linked. ${ }^{5}$ It was argued that researchers, as producers of 'power/knowledges', should also be aware of and reflect on the role of power in research processes. More specifically, this meant making visible the ways in which the research relationship was mediated and negotiated through the different positionalities of all participants.

A reflexive approach to conducting research has become an important way of taking into account and making visible the effect of research relationships in the final knowledge product. A reflexive approach attempts to provide an understanding of the relationship between the researcher and the researched in the research context. A specific outcome of this reflexivity has been a concern with how 'doing' research has the potential to oppress and exploit subjects. ${ }^{6}$ This awareness and concern about the impact of research is important and has produced innovative ways of 'doing' research; however, it has also produced a problematic dichotomy where the researcher is constructed as the 'powerful expert' and participants are understood to be 'powerless subjects'.

This aspect of poststructuralist and feminist methodological approaches was identified by Thapar-Björkert and Henry, who problematised the 'dualistic and binary mode of researcher/researched interaction ... which suggests that manipulation and exploitation only take place by the researcher'. ${ }^{7}$ While acknowledging the control we have as researchers over much of the research process and in the final research product, Thapar-Björkert and Henry argued that these approaches had not extended and applied notions of multiplicity to the research participant. ${ }^{8}$ The way power is exercised in the research relationship is constructed as unidirectional and the participant often becomes the 'oppressed victim' in such understandings. This problematic understanding of the research relationship has come about through two features of contemporary methodological practices, one relating to the institutional setting and the other around theoretical rigour.

Protecting participants from the researcher: university ethics procedures 
Institutionally, the 'powerful expert'/'powerless subject' dichotomy has arisen through the various university ethics processes that have been introduced over the last two decades. Winchester identified a number of important aspects of the research relationship that university ethics procedures cover, including:

consideration of possible trauma which may be experienced by respondents, and procedures for obtaining informed consent, provision for withdrawal without penalty, maintaining confidentiality, data safety and handling, and for returning information to the participants. ${ }^{9}$

Similarly, Israel and Hay note that ethics reviews offer a 'significant mechanism for stimulating ethical reflection' around issues of exploitation, conflicts of interest, controls over publication and researcher safety. ${ }^{10}$ All these ethical considerations are important and should be taken into account when designing, conducting and reflecting on the 'doing' of research. Indeed, as Israel and Hay point out, ethical reflection on the research process and its outcomes does not end with the approval number provided by an ethics committee. ${ }^{11}$ However, what is significant is that many of the aspects of the research process that concern university ethics procedures can inadvertently lead to the construction of the researcher as someone whose power needs to be constrained and regulated so as to not exploit the powerless participant. Rarely do university ethics procedures encourage researchers to think of participants as active shapers of the research nor do these guidelines promote the development of methodological approaches that would manage and enhance such engagement. The problem with this situation is that when constructing research participants as individuals that need to be protected from the researcher, university ethics procedures also serve to maintain the construction of the powerful/powerless dichotomy of the research relationship.

\section{Theoretical rigour}

The second methodological feature that has enabled this construction of the 'powerful expert' and the 'powerless subject' has been a lack of rigour in how researchers have employed Foucaultian understandings of power to the 'doing' of research. While Foucaultian understandings of the power/knowledge nexus have been innovatively applied, other aspects of his retheorisation of power-specifically 
the role of freedom and the rejection of distributional understandings of powerhave not been as well integrated into these methodologies.

Foucault provided a major challenge to the way power was conceptualised, urging a move away from distributional understandings of power as a 'resource' or 'capacity' to instead understand power as a relationship that only existed when it was exercised. Defining power as a relationship brought to the fore two particular features central to Foucault's understanding of power: knowledge and freedom. While the methodological literature has extensively applied the changed role of power/knowledge in the 'doing' of research, it has been the second aspectfreedom-that has not been as well integrated.

In previous understandings of power, freedom was conceived as some 'thing' that was relinquished when power was exercised. Foucault's notion of power inverted such understandings. ${ }^{12}$ Rather than being oppositional and destructive, the relationship between power and liberty was mutually dependent and productive. This understanding of the intimate relationship between power and freedom begins with the premise that power operates as a relationship: it is not a thing to be held by some at the expense of others' freedoms, but only transpires when it is exercised. Developing this further, power is only exercised when both parties in a relationship of power are free to act. As Foucault explained, 'power is exercised only over free subjects ... who are faced with a field of possibilities in which several ways of behaving, several reactions and diverse comportments may be realised'. ${ }^{13}$ Thus, where there is no freedom to (re)act, a relationship of power cannot exist and therefore power cannot be exercised.

The absence of an account of both knowledge and freedom in the reflexive analysis of research power relationships in the aforementioned methodological literatures results in such relationships being constructed as hierarchical and unidirectional, with power continuing to be constructed as a resource instead of relationship.14 For example, England referred to the research relationship as 'inherently hierarchical' and asserted that power relations in fieldwork were 'inevitably ... unequal'. ${ }^{15}$ Similarly, Rose presented power as something we could not 'fully ... control or redistribute.'. ${ }^{16}$ By treating power as a resource, where researchers have 'more' power and participants have 'less', reflexive responses have either involved researchers trying to 'empower' respondents through their research 
practices or discontentedly admitting the impossibility of their pursuit to 'equalise' the distribution of power. ${ }^{17}$

Smith has also critiqued these literatures for their 'rather simplistic assumptions about power', while Thapar-Björkert and Henry have argued 'there is a need within methodological debates to complicate the issues of agency, power and resistance in which the research participant could be similarly implicated as the researcher'. 18 One way of achieving this is through greater theoretical rigour and consistency in how power is understood. For poststructuralist methodological approaches this would involve rejecting the distributional understanding of power that does not take into account the freedom and ability of participants to influence and impact on the research relationship and the knowledge product that results from it. By doing this, researchers should also rethink the goal of 'empowerment' as an outcome of 'doing' research. This should be done for two reasons. First, as it stands, such an aspiration is theoretically inconsistent with poststructuralist understandings of power that have been so influential in reflexivity becoming an indispensable aspect of how we 'do' research. Second, when we seek to 'empower' research participants we fail to be open to recognising that these actors are already highly powerful shapers of the research projects they are part of. In the next section of this article I incorporate these additional aspects of research power relations to reflect on how the participants in my doctoral research on rural public housing in New South Wales were influential collaborators in how this research was conducted and how it developed.

\section{-THE MESSY ACTUALITIES OF RESEARCH RELATIONSHIPS}

Reflecting on my own 'doing' of rural research, there were a number of instances where participants influenced both how I acted during the research process and my perceptions of the research itself. In doing so, these rural participants were integral to how the research was conducted and influential in how I sought to represent the data I collected.

The first way that participants in this research project informed and influenced my own performances within the research was through their responses to the questionnaire. The questionnaire was initially designed to ask public housing tenants from the case study areas to volunteer to be part of the interview process. 
However, what I did not anticipate was the way that the responses from these questionnaires would influence my own behaviours and attitudes during the interview process. Specifically, a number of responses to the questionnaire demonstrated to me the high value participants placed on rurality. Usually the benefits of the rural were placed in direct juxtaposition to the negative aspects associated with metropolitan spaces and persons. For example, one respondent explained: 'I like the country it is small, not like the cities'. Similarly, another participant told me that she had 'No problems [with public housing] except for city guys coming to the country and trying to run it like the city-it does not work'. After receiving and analysing such responses to the questionnaire I was acutely aware of the value many participants placed on their rural location. It was important to me that participants did not view me as just another 'city' person who did not appreciate the value of the rural. As a consequence, during the conduct of these interviews I sought to emphasis my own ruralness, making sure I told participants of my own rural background and association with the case study region. Through their questionnaire responses, the participants in the research were active in informing how I constructed my own positionality within the interview context.

Participants also brought to this research project their considerable experience of participating in research projects. In particular, tenants were extremely au fait with the interview process. This familiarity can in part be explained by the fact that public housing tenants are regularly the focus of university, government and departmental research. As a New South Wales Department of Housing manager explained: 'There's always someone studying them.'19 While not denying the problematic aspects of public housing tenants being the focus of so much research, ${ }^{20}$ the wealth of experience that many tenants brought to this research made them extremely capable in terms of attempting to direct me in what they thought the research should be asking and the conclusions (especially the policy implications) that should arise from my work. Tenants were not afraid to tell me when they thought a question was redundant. For example, when asked about the gendered aspects of rural public housing many tenants sought to brush over or simply tell me how unnecessary such a question was. Similarly, tenants were quite strategic with the interview. Many used it as an opportunity to tell me what was wrong with public housing (for example, the lack of housing, who the housing was 
allocated to and so on) and what policy measures were needed to address their issues (such as the need to build more housing or the need for the department to regulate problematic tenant behaviours). As a result, I came away from the field with very little data on the gendered experiences of rural public housing but a plethora of interview material on how tenants understood the 'governance' of public housing at a variety of scales. The impact of the tenant participants' strategic uses of the interview process forced a re-evaluation of the research questions and the eventual decision to abandon the original research focus on the role of gender in rural public housing communities, refocusing the work on the declining provision of public housing in New South Wales and the impact of this on rural tenants.

The New South Wales Department of Housing staff who participated in this research also used the interview as a strategic opportunity. At the time of the interviews, staff were facing another series of departmental reforms. Within this context, many of the staff used the research as an informal opportunity to vent their fears and frustrations with a reform process they felt little control over. Initially, I had sought interviews with Department of Housing staff to simply obtain another perspective on the experiences of rural public housing tenants. However, after this group of research participants communicated their fears of the impact of these reforms-including the closure of their offices, the potential loss of jobs and loss of colleagues, and the implications these changes had on their ability to remain in their rural locations-I felt that these were issues I could not ignore when it came to 'writing up' the research. Eventually, a whole chapter was devoted to the issues staff had with the reform process. However, if staff had not sought to strategically use the interview in this way the research would never have examined this aspect of the delivery of rural public housing. The research experience with Department of Housing staff differed from the interview experiences I encountered with the public housing tenants. This was because a different 'modality' of power could be seen to be exercised in this research relationship. ${ }^{21}$ With the tenant interviews I was 'forced' to change the research project as I had very little data to use if I did not make the change. In the case of the interviews with staff, because I had the ability to 'opt out', I was not so much 'forced' as 'seduced' to include these narratives in the final research product. ${ }^{22}$ 
These research relationships speak more broadly to concerns raised by 'new working class studies' that argue the importance of not presenting the working class as an 'entirely passive victim' in processes of social, political and economic change. ${ }^{23}$ In this case, 'working classness' can be seen as an important element that informed how participants engaged in the research. For tenants, their working classness emerged through the fact that it was certain economic measures established by the NSW Department of Housing (such as income and employment status) that meant they were eligible for and allocated public housing and therefore invited to participate in the research. These economic measures of 'class' can also be seen to inform how tenant participants understood public housing more widely, their position within public housing communities, and how they believed public housing could be improved. Department of Housing staff also employed their 'classness' through the fact that it was their 'job' and its security that informed a significant part of their interactions with me. In both instances, the 'classness' of public housing tenants and staff informed a radical shift in my own research objectives and conclusions, away from a concern with gender and towards a more traditional concern of political-economic restructuring, social justice and redistribution.

In the 'doing' of this rural research participants radically changed the focus of the research through the various ways they responded to the questions being asked of them, negotiated the research relationship and made their own strategic uses of the interview process. Because of their influence and impact on the research, it is hardly representative to speak of the research as having 'empowered' these participants when, in many cases, these individuals were already capable and active in negotiating, reforming and strategically using the research process. The additional elements of Foucault's understanding of power-freedom and a nondistributional approach to power-brought a new perspective to the 'doing' of this rural cultural research. In particular, it showed how significant the participants in this work were to how the research developed and to the final outcomes and conclusions.

\section{-CONCLUSIONS}

This article has sought to consider how theoretical understandings of 'power' are important to how we reflect on and construct the research relationship in 'doing' 
rural cultural research. In undertaking these reflections, however, I do not wish to shift research participants from one homogenised category to another; from 'powerless' to 'all powerful'. Nor do I wish to disregard the material and sociocultural differences that impact on how research relationships are negotiated. My argument is that by being more explicit in what we mean by power, by abandoning the theoretical ambiguities of power that are currently present in the methodological literatures referred to in this paper, we are in a better position to reflect on the various power relationships that exist within the doing of research. As researchers reflecting on the 'doing' of rural cultural research we need to be as aware of how participants exercise power in the research relationship as much as we do as researchers. The 'doing' of research is not the exclusive domain of the researcher. As this article has outlined, the rural public housing tenants and Department of Housing staff I interviewed brought to the research their own subjective understandings of what the research should be, how the interviews should be conducted, and how their own political agendas could be served through their participation.

There are a number of implications for 'doing' research when we choose to explicitly understand power as a relationship - not a resource-that is exercised between two individuals that are 'free'. First, we become more attuned to the way in which the research relationship is negotiated by all parties. For example, I became aware of the ways that subjects saw me as an opportunity to generate a specific political agenda, or the ways they redirected the concerns of my research. Such actions were not those of people without power, but the outcomes of a relationship of power being exercised. Second, we become aware of the way in which other power relationships and governmental processes inform how respondents negotiate the research situation-for example, the ways rural public housing tenants responded to the interview based on their other experiences of research conducted by the New South Wales Department of Housing. Finally, the notion of 'empowerment' as a goal of research and all its distributional implications should be critically re-evaluated. Such an approach makes space for researchers to acknowledge that our own experiences of uncertainty and discomfort in the field are inevitable outcomes of relationships of power where we are not simply the 'powerful experts'. These experiences place us in a research/power relationship 
where we are not in control but are free to act and react to the (re)actions of those we engage with in the field. While attempts to 'empower' research participants are pursued with the best intentions, they remain problematic because they continue to construct participants as 'powerless' in our research. For this researcher, there was something more representative of my own rural research experiences in understanding participants as active shapers of the research process and the end product.

Rae Dufty is a lecturer in the Department of Geography and Planning at the University of New England. She completed her doctoral work on the distributional politics of rural public housing in Australia in 2008. <rdufty@une.edu.au>

\section{-ACKNOWLEDGMENTS}

I am deeply grateful to those respondents who answered the questionnaire and volunteered to be interviewed as part of this research. I would also like to thank the participants of the 'Doing Rural Cultural Studies' workshop, members of the University of Newcastle's Geography Department, Associate Professor Neil Argent and two anonymous reviewers who provided invaluable feedback and encouragement on earlier drafts of this paper.

\section{-NOTES}

1 Participants names have been changed for privacy

2 While this article is specifically concerned with the 'doing' of rural cultural research, the audience at a recent presentation of this work (University of Newcastle, NSW, 26 March 2009) felt that the findings and conclusions of the paper could be more generally applied to the broader 'doing' of human geographical and cultural research, in particular the 'doing' of in-depth interviews.

3 See, for example, Terry Threadgold, 'Poststructuralism and Discourse Analysis', in Alison Lee and Cate Poynton (eds), Culture and Text: Discourse and Methodology in Social Research and Cultural Studies, Allen \& Unwin, Sydney, 2000, pp. 40-58; J. K. Gibson-Graham, “'Stuffed if I Know!”: Reflections on Postmodern Feminist Social Research', Gender, Place and Culture, vol. 1, no. 2, 1994, pp. 205-24; Nancy Naples and Carolyn Sachs, 'Standpoint Epistemology and the Uses of Self-reflection in Feminist Ethnography: Lessons for Rural Sociology', Rural Sociology, vol. 65, no. 2, 2000, pp. 194-214; Barbara Pini, 'Feminist Methodology and Rural Research: Reflections on a Study of an Australian Agricultural Organisation', Sociologia Ruralis, vol. 43, no. 4, 2003, pp. 418-33.

4 Michel Foucault, 'Truth and Power', in James Faubion (ed.), Michel Foucault: Power-Essential works of Foucault 1954-1984, vol. 3, Penguin, London, 1994, pp. 111-33.

5 Michel Foucault, 'Truth and Juridical Forms', in James Faubion (ed.), Michel Foucault: PowerEssential works of Foucault 1954-1984, vol. 3, Penguin, London, 1994, pp. 1-89.

${ }^{6}$ Gillian Rose, 'Situating Knowledges: Positionality, Reflexivities and other Tactics', Progress in Human Geography, vol. 21, no. 3, 1997, pp. 305-20; Robyn Dowling, 'Power, Subjectivity and Ethics in 
Qualitative Research', in Iain Hay (ed.), Qualitative Research Methods in Human Geography, Oxford University Press, South Melbourne, 2005, pp. 19-29.

7 Suruchi Thapar-Björkert and Marsha Henry, 'Reassessing the Research Relationship: Location, Position and Power in Fieldwork Accounts', Social Research Methodology, vol. 7, no. 5, 2004, p. 363. See also Linda McDowell, 'Elites in the City of London: Some Methodological Considerations', Environment and Planning A, vol. 30, 1998, pp. 2133-46 and Katherine E. Smith, 'Problematising Power Relations in "elite" interviews', Geoforum, vol. 36, 2006, pp. 643-53.

8 Thapar-Björkert and Henry, p. 377.

9 Hilary P. M. Winchester, 'Ethical Issues in Interviewing as a Research Method in Human Geography', Australian Geographer, vol. 2, no. 1, 1996, p. 128.

10 Mark Israel and Iain Hay, Research Ethics for Social Scientists: Between Ethical Conduct and Regulatory Compliance, Sage, London, 2006, p. 130.

11 Israel and Hay, p. 130.

12 Michel Foucault, 'The Subject and Power', in Hubert Dreyfus and Paul Rabinow (eds), Michel

Foucault: Beyond Structuralism and Hermeneutics, Harvester, Brighton, 1982, pp. 208-26.

13 Foucault, 'The Subject and Power', p. 211.

14 It is important to note that the predominance of advice about 'disempowered' research participants stems from many researchers' long-term focus on those who are disenfranchised, oppressed, exploited and so on. As a consequence we have tended to assume that participants' positions in social or economic hierarchies carry over to the research relationship.

15 Kim V. L. England, 'Getting Personal: Reflexivity, Positionality and Feminist Research', Professional Geographer, vol. 46, no. 1, 1994, p. 86.

16 Rose, p. 319.

17 Jennifer Daryl Slack and Laurie Anne Whitt, 'Ethics and Cultural Studies', in Lawrence Grossberg, Cary Nelson and Paula Treichler (eds), Cultural Studies, Routledge, New York, 1992, pp. 571-92;

Melissa Gilbert, 'The Politics of Location: Doing Feminist Research at “Home"', Professional Geographer, vol. 46, no. 1, 1994, pp. 90-6.

18 Smith, p. 644; Thapar-Björkert and Henry, p. 365.

${ }^{19}$ Kristian Ruming, Kathleen Mee and Pauline McGuirk, 'Questioning the Rhetoric of Social Mix: Courteous Community or Hidden Hostility', Australian Geographical Studies, vol. 42, no. 2, 2004, pp. 234-48.

20 See in particular Paul Rabinow's critique of the role of the social sciences in collecting data on sub/deviant/different-populations in Paul Rabinow, 'Introduction', in Paul Rabinow (ed.), The Foucault Reader: An Introduction to Foucault's Thought, Pantheon, New York, 1984, p. 8.

21 John Allen, Lost Geographies of Power, Blackwell, Maldon MA, 2003.

22 Allen, p. 31.

23 Tim Strangleman, 'Sociology, Social Class and New Working Class Studies', Antipode, vol. 40, no. 1, 2008, p. 17. See also Alison Stenning 'Intervention Symposium: Geography and New Working Class Studies', Antipode, vol. 40, no. 1, 2008. 